\title{
Epistemic Modality in Selected Presidential Inaugurals in Ghana
}

\author{
Cletus Komudayiri Kantorgorjeㄹ, Peace Chinwendu Israel'1, Peter Mwinwelle² \\ ${ }^{1}$ University of Education, Winneba, Ghana \\ ${ }^{2}$ Koforidua Technical University, Koforidua, Ghana \\ Email: kantorgorjecletus@gmail.com, peacenwendu@gmail.com,pmwinwelle@gmail.com
}

How to cite this paper: Kantorgorje, C. K., Israel, P. C., \& Mwinwelle, P. (2021). Epistemic Modality in Selected Presidential Inaugurals in Ghana. Open Journal of Social Sciences, 9, 154-168. https://doi.org/10.4236/jss.2021.96013

Received: April 30, 2021

Accepted: June 19, 2021

Published: June 22, 2021

Copyright (c) 2021 by author(s) and Scientific Research Publishing Inc. This work is licensed under the Creative Commons Attribution International License (CC BY 4.0).

http://creativecommons.org/licenses/by/4.0/ (c) (i) Open Access

\begin{abstract}
This paper employed the qualitative research approach to investigate the use of epistemic modality (EM) in four selected inaugural speeches of ex-presidents in the fourth republic of Ghana. It was underpinned by the interpersonal metafunction in Hallidayan's (1994) Systemic Functional Linguistics (SFL) theory which dovetails into the concept of EM. The analysis was done with the aid of corpus-based computer software-AntConc. The findings revealed a preponderant use of modal verbs with a frequency of 165 representing $84.2 \%$ while lexical verbs occur 13 times representing 6.6\%. Adjectives and adverbs are minimally used with a frequency of 11 and 7 representing $5.6 \%$ and 3.6\% respectively. The findings also revealed that Ghanaian presidents in the fourth republic dominantly use high values of EM to present themselves as bold, confident, committed and forthright in their utterances. Additionally, they were also communicatively sensitive as they use tentative markers when addressing sensitive issues. The study bears implications for pedagogy, theory and practice as it boosts the concept of EM and its appropriate use in political discourse.
\end{abstract}

\section{Keywords}

Political Discourse, Epistemic Modality, SFL, Interpersonal Metafunction

\section{Introduction}

Political discourse is a major discourse in every society because it has the capability to either hold together or disintegrate the society. Since language cannot be divorced from human existence, the study of how language operates in a society is very crucial. Politics is generally considered as the use of language to organize people's mind and reorient their opinions and beliefs about a subject/topic. It is 
thus an instrument to control the conscience of the society. It is for this reason that Wilson \& Sperber (2001) postulates that a political discourse is a complex cross-disciplinary enterprise which explores the social, psychological, cultural, ideological and linguistic factors. Nemickiene (2019) adds that political discourse is a formal, oral or written discussion of different factors such as politicians and organizations to citizens by making use of a variety of methods to cleverly influence, supervise and impact a population. Zheni (2019) indicates that a discourse is political when it performs political acts in political institutions such as, electoral campaigns, manifestos, inaugurals, state of the nation addresses and parliamentary debates. It is thus a discourse that affects the ways political factors such as presidents convey social meanings and make rhetorical and linguistic choices in order to align themselves with the audience and to legitimize their ideological views and power status. Opeyemi \& Ajoke (2019) also strengthen this view by suggesting that language plays a vital role in this interactional process as every political action is prepared, accompanied, influenced and played by language. Politicians are therefore very careful in their choice and use of linguistic strategies/devices.

The most notable functions of any political speech are to inform, move, persuade and to inspire the audience to take action. The level of confidence or commitment to a proposition or what is said, is what Coates (1983) refers to as epistemic modality (EM). Hoye (1997) avers that in the attempt to express their convictions or assessment of a proposition in terms of their truth-value or otherwise, public speakers, especially political actors, use epistemic modals to indicate their commitment, confidence, knowledge or lack of it in a proposition. This is because epistemic modal markers-bearers of epistemicity are used for two main reasons: "content-oriented caution" and "addressee-oriented caution" (White, 2003). While "content-oriented caution" indicates a speaker's uncertainty about the content of his utterance, "addressee-oriented caution" signals a speaker's hedgeness for pragmatic reasons. The linguistic categories that usually encode the notion of EM are modal auxiliaries, semi-auxiliaries, modal lexical verbs, modal adjuncts, imperative mood, subjunctive mood and non-linguistic cues (Palmer \& Jakobson, 1974; Nordquist, 2003). Therefore EM leaves room for "others" opinions and usually marks various levels of certainty or commitment in the continuum of belief or trust of a proposition. It is in line with this backdrop that the present study explores the use of EM markers by presidents in their inaugurals.

Inaugurals are political speeches which serve as a means of establishing and maintaining social relationships, expressing feelings and selling ideas, policies and programmes in any society by its leaders. An inaugural speech marks the beginning of a new regime in a particular republic. It is characterized by a call for unity and support, a promise of a better future, appreciation of the efforts of past presidents and/or a condemnation of the bad governance of their predecessors. 
Until recently, Ghana has had a checkered political history after her independence. This is because in her sixty-two (62) years of nationhood, she has experienced four republics with many regimes of governments. A republic is a constitutional era or time in the life of a country where its political actors are democratically elected. It ends when the constitution is abrogated or overthrown through an unconstitutional means. The first republic in Ghana was from 1960 to 1966 under the presidency of Kwame Nkrumah; the second was from 1970 to 1972 with Edward Akufo-Addo as President; the third from 1979 to 1981 under the presidency of Hilla Limann, and the fourth republic commenced 1993 to date (2021) under the leadership of various presidents. The fourth republic has been the longest and has experienced seven (8) inaugural speeches. Two each were given by Presidents Jerry John Rawlings (1993 to 2000) and John Agyekum Kufuor (2001 to 2008) who served two terms each of four years. President John Evans Atta Mills (2009 to 2012) who died in office gave one, while his successor, President John Dramani Mahama (2012 to 2016) who served only one term in office, also gave one. The current president, President Nana Akufo Addo has delivered two. First was in 2017 and the latest inaugural speech was delivered on 7 January, 2021 as he assumed office for his second term. It is within the fourth republic that this work is contextualized and the selected speeches are drawn from this period.

\section{Statement of the Problem}

There has been an avalanche of studies in political discourse relative to modality and Systemic Functional Linguistics (SFL) (Jantuah, 2008; Pham, 2010; Adu, 2015; Xu, 2015; Israel \& Botchwey, 2017; Zeng \& Wang, 2019; Opeyemi \& Ajoke, 2019; Hardjanto \& Mazia, 2019; Nemickiene, 2019). Out of these, a few were close to the present study such as Adu (2015) who conducts an EM analysis of selected State of the Nation Address (SONA) of President John Agyekum Kuffour of Ghana and Opeyemi \& Ajoke's (2019) study of linguistic modality analysis of the inaugural speech of president Nana Akuffo Addo of Ghana. They are similar in the sense that while Opeyemi \& Ajoke (2019) situate their work in an inaugural speech, Adu (2015) applies the analysis of EM to SONA. However, to the best of the knowledge of the present researchers, there is no known work on the analysis of EM in the inaugurals of Ghanaian presidents in the fourth republic aided by corpus linguistic tools. Therefore, this lacuna is thus filled by this study via a corpus-based methodology to unearth the strengths and communicative impacts of EM.

\section{Objectives}

The Objectives of this study are to:

- examine the frequency of occurrence of EM markers in the selected presidential inaugural speeches in the fourth republic of Ghana.

- examine the communicative functions of EM in the inaugural addresses. 


\section{Questions}

This research seeks to answer the following research questions

- What is the frequency of occurrence of the epistemic modal markers in the selected presidential inaugural speeches in the fourth republic of Ghana?

- What communicative functions underpin the use of EM in the inaugural addresses?

\section{Theoretical Framework}

This study is conducted under Halliday's (2004) Systemic Functional Linguistics (SFL) theory using specifically his model of EM known as modalisation in the interpersonal metafunction. SFL deals with how language is orderly organized or patterned and used to meet the needs of the individual and the society at large. These functional purposes of language are what Halliday technically terms as the semantic metafunctions of language which simultaneously act together to produce the morphology and semantics of a discourse. These Metafunctions are ideational, interpersonal and the textual Metafunctions. The clause is usually the fundamental unit of operation in these metafunctions (Halliday, 1971, 1978, $1985,2004)$. The ideational function deals with how the world and our experiences are enacted or represented in a text. Halliday (1971) states: "it is through this function that the speaker or writer embodies in language their experience of a phenomenon of the real world." The interpersonal metafunction deals with the interaction or relationship between the participants or the interlocutors in a text in relation to the meaning they each make of a particular text or discourse. The textual function of language deals with how language has been used to organize or construct the text itself. Halliday (1971) maintains that the textual function in language has to do with a set of options by which a speaker or a writer is enabled to create and use language in a way that is relevant to a specific context.

Though these three metafunctions complement each other to create a communicative unit, there are some linguistic resources that usually help to highlight the role of one over the other in a particular text or discourse. In political texts such as inaugurals for instance, it is the interpersonal metafunction that is usually projected more through the pervasive use of EM devices. According to Flowerdew (1998) the interpersonal function is concerned with the writer's or speaker's attitude and level of commitment to the message or proposition being expressed which corresponds to the notion of modality (epistemic and deontic). It deals with the use of language to encode an interaction with the aim of sustaining the relation among participants in a communication to achieve a communicative end. These participants are the speaker (cover term for both speaker and writer) and the audience (listeners and readers) who usually set up communicative roles which allows them to engage in various communicative acts such as informing, questioning, greeting, persuading, condemning, eulogizing. Halliday (1994) indicates that language is often used to exchange information or give goods and services in this kind of interaction. 
Palmer (1989) expound that the interpersonal meanings are meanings which express a speaker's attitude and judgment about a proposition and that these meanings are for acting up on and with others. He maintains that modality deals with the attitude that is being expressed about a proposition. It is therefore significant to note that in the interpersonal metafunction, language is used in the exchange of information to maintain social relations by demonstrating the various roles played by the participants. To be able to achieve or realize this interpersonal metafunctional goal especially in a political discourse, the modality system is usually activated and adopted since it deals with people's attitudes, opinions and judgments about a proposition. In Halliday's SFL theory, while the experiential metafunction is expressed by the transitivity system, the interpersonal metafunction is expressed by the modality system.

According to Halliday (1994), modality is the intermediate degree between the positive and negative poles of a proposition or the distance that lies between the yes and no of a proposition which normally is referred to as the modal distance or space. Fowler (1983) states that: "Epistemic Modality is the grammar of explicit comment. It is the means by which people express their degrees of commitment to the truth of the proposition they utter, and their views on the desirability or otherwise of the states of affairs referred to". This implies that the system of EM (modalisation) enables speakers or writers to assert or deny their proposition with varying degrees of certainty about the likelihood (possibility, probability, certainty etc.) of something and the frequency (sometimes, usually, always etc.) of something. To make a purposive use of EM in the interpersonal metafunction, three variables usually interplay-system of type, value and orientation (Halliday \& Matthiessen, 2004).

The system of type categorises modality into two types: modalisation and modulation which are synonymous to epistemic and deontic modality respectively in traditional grammar. Modalisation expresses a degree of probability and usuality while modulation expresses the degree of obligation and inclination. In modalisation which is the focus of this study, the speaker makes a statement or question about information (proposition) to the listener. It also expresses the validity of the meanings of a proposition in terms of probability (how likely something is true) and usuality (how frequent or often something is true). There are three ways by which modalisation (epistemic modality) can be expressed in the clause or in a proposition:

1) The use of a Finite modal operator or verb (might, ought to, must, etc.) e.g. Peter might have taken the book.

2) The use of Mood Adjuncts or adverbs (possibly, probably, certainly, etc.) e.g. Ezinne is probably a good writer.

3) The use of both: a Modal Finite and a Mood Adjunct e.g. That man will (modal finite) probably (modal adjunct) need your help.

The value of modality has to do with the level/degree of assertiveness of the choice of a particular modal expression-high, median or low. These three labels/values are very useful because they help to determine the degree to which a 
speaker commits himself to the validity of a proposition. They also reveal how far a speaker overtly accepts responsibility for the opinions being expressed towards a proposition (Thompson \& Hunston, 2004).

The orientation modality shows various ways speakers choose to express their opinions about a proposition which could be subjective or objective, implicit or explicit depending on how the speaker construes the clause. Objectivity is usually content oriented while subjectivity is subject oriented; that is, meaning is constructed from the speaker's lens. While the objective orientation deals with modulation, the subjective orientation is connected to modalisation.

Table 1 indicates Halliday's (2004) model or concept of EM (modalisation).

From Table 1, the concept of modalisation by Halliday (2004) looks at the realization of probability (epistemicity) from two main complementary angles-levels and usuality relative to certain specific linguistic choices. When the strength /level of probability is high, medium or low, there is a corresponding usuallity marker to confirm the strength or weakness of a particular utterance which also affects the meaning that is intended for the listeners. For instance when the probability or the continuum of epistemicity is realized as high and the usuallity of occurrence is always and often, then a speaker is considered confident and trustworthy. The linguistic items on the table are composed of three classes of words i.e. modal verbs, modal adverbs and modal verbs with adverbs put together.

In summary, the theoretical framework looks at how language is used to perform various functions from the linguistic system that one possesses. One's choice in this linguistic system enables us to know one's attitude towards a proposition which goes to affect listeners' meaning either negatively or positively. This speaker-listener relationship is what is described as interpersonal metafunction which this study is hinged on.

\section{Methodology}

The choice of the fourth republic was based on the grounds that it is the most stable and peaceful among all the republics of the country. The purposive sampling technique was used to sample four out of the seven inaugurals of the fourth republic. The four speeches are those given by John Agyekum Kufuor $\left(7^{\text {th }}\right.$, January 2001), John Evans Atta Mills (7 January, 2009), John Dramani Mahama ( $7^{\text {th }}$

Table 1. Halliday (2004) model of EM (modalisation).

\begin{tabular}{lll}
\hline \multicolumn{1}{c}{ Realization } & \multicolumn{1}{c}{ Median } & Low \\
\hline $\begin{array}{l}\text { must, certainly, sure, believe, } \\
\text { Probability definitely, can't, couldn't, bet } \\
\text { of course, shall }\end{array}$ & $\begin{array}{l}\text { probably, probable, think, } \\
\text { will be, wont, should believe }\end{array}$ & $\begin{array}{l}\text { maybe, possibly, may, } \\
\text { perhaps, can }\end{array}$ \\
Usuality Always & usually, often, frequently & $\begin{array}{l}\text { sometimes, occasionally, } \\
\text { ever, once, seldom, } \\
\text { rarely }\end{array}$ \\
\hline
\end{tabular}


January, 2013) and Nana Akufo Addo ( $\left.7^{\text {th }} J a n u a r y ~ 2017\right)$. The speeches were retrieved from credible Ghanaian news websites: www.myjoy.online.com and www.dailygraphic.com and to ensure credibility, copies were also taken from the national newspapers: the Daily Graphic and the Ghanaian Times from the archive section of public libraries in Accra, Ghana. To ensure political balance, speeches of Presidents John Agyekum Kufuor and Nana Akufo Addo represented the National Patriotic Party (NPP), while Presidents John Evans Atta Mills and John Dramani Mahama represented the National Democratic Congress (NDC), the two major political parties in Ghana.

The four sampled inaugurals were read, processed and fed into the computer software known as AntConc for analysis. The data was processed by deleting all the titles, pictures, tables and direct quotations found in the speeches since they do not form part of the body of the text which contains the EM markers. For easy identification of each text in the corpus, a coding system was developed. The four speeches were converted from Microsoft word to plain texts. This is because as Baker (2014) points out, most corpus analysis software at present works best with this format; although other options like Rich text and XML can be used. It should be noted that corpus analysis tools do not read digital texts in $p d f$ or word format, only plain text. The uploaded text was the subjected to sentential sorting by closely reading them line by line in the software to get rid of non-epistemic line. Randomly sampling the linguistic items in Table 1, two main searches were made using AntConc tools. First, using the frequency tool, we were able to determine the frequencies of each of the sampled linguistic items. Secondly, the contextual meaning of each of these linguistic items was arrived at by deploying the concordance tool of AntConc. These tools helped us to arrive at unbiased interpretations and conclusions.

\section{Analysis and Discussion}

The analysis and discussion of data centres on the identification of various EM markers in selected speeches based on how such markers express different degrees of epistemic stance which is in relation to their epistemic distance towards the centre of certainty. The EM markers were identified based on parameters such as structure (Coates, 1983), context (Collins, 2009) and personal idiosyncrasy (Lyons, 1977). The structural mode looks at the syntactic structure of an epistemic proposition as having all or some of the following: an inanimate or an existential subject, a stative verb(s) and may be in the passive voice. The context details the environment in which EM markers occur while the personal idiosyncrasy is based on the personal judgement of the individual. The analysis follows up with the discussion of the frequency of occurrence of the identified EM markers together with the communicative meanings underpinning the use of such markers.

\subsection{Distribution of EM Markers in the Selected Speeches}

Our objective one was to examine the frequency of occurrence of EM markers in 
the speeches. With the aid of the frequency tool in AntConc, a total number of seven thousand eight-hundred and twenty-eight (7828) words or tokens made up of the corpus. These were distributed thus Akuffo Addo-2673 tokens, Mills-1111 tokens, Kufour-315 tokens and Mahama-1729 tokens. It is within this volume of data that linguistic forms from Halliday's (2014) model of EM (modalisation) were used. Table 2 indicates the overall frequency of the various linguistic category or forms of language that were deployed epistemically in the data.

From the table above, it is obvious that modal verbs are the most used EM forms or markers in the fourth republic of Ghana with a frequency of 165 counts representing $84.2 \%$. The least in the use of this category is Mills with a count of 35. This very high occurrence of modal verbs resonates with other researchers such as Nuyts (2001), Xu (2015), Perkins (1983) and Hoye (1997) who posit that modal verbs are the most frequently used markers of EM in political discourses. The reason for this high frequency of modal markers, they argue, is not far-fetched. While Hoye (1997) explains that they are clearly set-out and their boundaries of determining meaning are clearly defined, Perkins (1983) adds that they are less fuzzy and have straightforward means of expressing modality especially EM.

Again, when the top-five modal verbs were analysed epistemically due to this linguistic category dominance in the data, Table 3 was realised.

In all, there were a total of 216 instances of modal verbs use discovered in the data. However, upon a closer look, 165 of them were used epistemically while 51 did not indicate any epistemic sense. This close study revealed that one modal

Table 2. Overall distribution of forms of EM.

\begin{tabular}{ccccccc}
\hline Epistemic form & Mahama & Mills & Kufour & Nana & Total & Percentage (\%) \\
\hline Modal Verbs & 35 & 28 & 40 & 62 & 165 & 84.2 \\
Lexical Verbs & 4 & 1 & 3 & 5 & 13 & 6.6 \\
Adverbs & 2 & 1 & 2 & 2 & 7 & 3.6 \\
Adjectives & 2 & 0 & 4 & 5 & 11 & 5.6 \\
Total & 61 & 30 & 49 & 74 & 196 & 100 \\
\hline
\end{tabular}

Table 3. The use of top-five epistemic modal verbs in the speeches.

\begin{tabular}{ccccccc}
\hline Modal verb form & Mahama & Mills & Kufour & Nana & Total & Percentage (\%) \\
\hline Must & 6 & 2 & 8 & 14 & 30 & 18.2 \\
Can & 6 & 1 & 4 & 7 & 18 & 10.9 \\
May & 3 & 1 & 1 & 2 & 7 & 4.2 \\
Will & 16 & 24 & 13 & 32 & 85 & 51.5 \\
Shall & 4 & 0 & 14 & 7 & 25 & 15.2 \\
Total & $\mathbf{3 5}$ & $\mathbf{2 8}$ & $\mathbf{4 0}$ & $\mathbf{6 2}$ & $\mathbf{1 6 5}$ & 100 \\
\hline
\end{tabular}


verb can play more than one modality function. This finding goes to buttress the point made by Vold (2006) that one modal verb can express more than one modality meaning since the context is the major determinant of its specific use. In fact, Leech \& Svartvik (1997) describes them as polysemous in nature and that this allows them to be deployed to achieve specific communicative intents and purposes in a political discourse.

Again in the area of epistemic strength or value, Table 4 indicates how each president fared.

In Table 4, no one president topped in all the levels. While Akuffo Addo appears to be more confident and committed to propositions he makes, Kuffour and Mahama lacked full commitment and confidence in their propositions; they were more tentative and diplomatic. This may probably be because they want to evade a potential responsibility if their epistemic judgments turn out to be wrong (Hart \& Cap, 2014). It again shows the uniqueness and demeanour of each president. Because EM markers of high value are dominant, it can be concluded that presidents in the fourth republic are very confident and bold.

\subsection{Communicative Functions of EM Markers in the Selected Speeches}

Objective two was to examine the communicative functions of the EM. In terms of frequency of occurrence, EM markers play three fundamental functions in the speeches: stance taking, politeness and image construction. Stance-taking for $\mathrm{Xu}$ (2015) indicates the stance that a speaker (president) takes in relation to a claim or a proposition they make. This is usually based on the amount of information and knowledge one has concerning a particular proposition. The politeness function is usually based on the face act theory of Brown \& Levison's (1987) which deals with the pragmatic function of language usage. So, the more assertive or high EM markers are used, the more listeners perceive speakers as being proud and insensitive. The constructive function looks at how an epistemic marker can be used to construct speaker identity and speaker-listener relationship.

Three major functions were demonstrated in the data from the perspectives of the three values of EM relative to epistemic distance in the context of the interpersonal metafunction (Bybee \& Fleischman, 1994). The communicative functions can be related to their scales, levels or values which range from high to low-how the speakers' beliefs, ideologies and opinions are formulated and graded

Table 4. The use of epistemic values in the four inaugurals.

\begin{tabular}{ccccccc}
\hline Epistemic level/value Mahama & Mills & Kufour & Akuffo Addo & Total & Percentages (\%) \\
\hline High & 24 & 27 & 31 & 54 & 136 & 65.4 \\
Medium & 12 & 1 & 16 & 11 & 40 & 19.2 \\
Low & 14 & 2 & 6 & 10 & 32 & 15.4 \\
Total & $\mathbf{5 0}$ & $\mathbf{3 0}$ & $\mathbf{5 2}$ & $\mathbf{8 5}$ & $\mathbf{2 0 8}$ & $\mathbf{1 0 0}$ \\
\hline
\end{tabular}


along the various force of epistemicity - certain, probable, and possible-during the persuasion processes (VanDijk, 2011).

\subsubsection{EM of High Value: Close to Certainty}

Because modal markers were highly used to indicate this level, the two most frequently used epistemic modals randomly extracted from the concordance lines were will and must. Will is the most popular EM marker used by all the selected presidents with a count of 85 instances. According to Klinge \& Muller (2010), will is regarded as a vague marker when it comes to semantics because it can suggest various meanings such as volition/intention, high possibility or both and so agrees with Coates (1983) who believe that context and personal judgement is the only possible way to separate volitional will from prediction will. Must has a count of 30 epistemic uses. Collins (2009) equates epistemic will to epistemic must in political discourse but states that must express a confident conclusion, which Palmer terms "deductive", i.e. "the only possible conclusion" (Palmer, 2001). Here are some extracts from the data:

1) Together we will build a Ghana that will be a source of pride for all of us (J.

\section{MAHAMA2013)}

2) Our public service will be accorded the dignity and respect it deserves. (N. AKUFO ADDO2017)

3) The law will be allowed to take its course. (J. E. A. MILLS2009)

4) Our pride will be even more justified when we have put our economy on sound footing. (J. A. KUFUOR2001).

5) Being a Ghanaian must put certain responsibilities on each of us. (N. AKUFO ADDO2017)

6) More jobs must be created for our people. (J. D. MAHAMA2013)

7) Fear must be banished from our public and political life. (J. A. KUFUOR2001)

8) Fellow citizens you must be at the centre of change. (J. E. A. MILLS2009)

\subsubsection{EM of Intermediate Value: Near-Probable}

This marker is used when the certainty of the status of affairs is probable and unsure. It is mid-way between certainty and uncertainty/doubt. Simon (1997) describes this level as neutral which expresses partial commitment on the part of the speaker to their statements or proposition. Pragmatically, the users of this category of EM markers are considered diplomatic, measured and polite. It also shows a leader who is evasive and irresponsible. With a total of 40 frequency counts representing $19.2 \%$ of the EM markers, this level (medium) value comes next to high level. The dominantly used linguistic EM here are the modal should and lexical believe.

Campbell \& Jamieson (2008) note that should is generally used to indicate epistemic stance of probability. Thus the stance and the knowledge that a speaker has about a proposition are unsure and largely unreliable. It is not surprising therefore that Halliday (2004) and Ngula (2015) rightly classify this marker (should) under the medium value of EM which indicates a sense of partial com- 
mitment to a proposition. Believe is typically used to indicate a personal knowledge of the possibility of an utterance. The speaker uses it based on some knowledge, feelings or instincts that he has in connection with possibility or otherwise of a proposition. Because the knowledge or source of evidence for the proposition is uncertain and sometimes based on intangible reasons, believe is usually considered to be a very subjective and unscientific way of passing judgement on a proposition.

Semantically, they indicate weak and tentative epistemic judgements. Pragmatically, speakers who use markers of these sorts are considered as people who are not confident and cannot be fully trusted or taken seriously. They are also people who do not have full facts and knowledge of their statements. Diplomatically however, they are considered as considerate, polite and measured in their utterances hence endearing them to their listeners.

The following are instances of their use in the corpus:

1) Nothing should stand in the way and I promise that my administration will give all the help needed to enable the police get to the bottom of these gruesome murders. (J. A. KUFUOR2001)

2) We should all recognise the danger we face by the alarming degradation of our environment. (N. AKUFO ADDO2017)

3) Equipment should not be the only thing that is state of the art in our institutions. (J. D. MAHAMA2013)

4) I believe a consensus is emerging that we must decentralise more. ( $\mathrm{N}$. AKUFO ADDO2017)

5) I believe this because I have seen the work and accomplishments of my predecessors. (J. D. MAHAMA2013)

6) I believe that as a nation, we will find the strength of character, ... to accomplish even the most difficult of task. (J. E. A. MILLS2009)

7) I believe that is why you have been in the forefront of the democratic revolution. (J. E. A. MILLS2009)

\subsubsection{EM of Low Value: Far From Certainty}

This EM marker is used to express weak and tentative commitments. In epistemic distance, it is placed very remotely from certainty as the speaker has very little or no knowledge about what he is saying or may just want to be polite. In the corpus, the number of EM markers which represent this epistemic value is 32 counts representing $15.4 \%$ of the total instances in the data. The two most dominant markers of this category are may and could with their variants might and can. May is used to avoid committing oneself to the truth of a proposition (Coates, 1983). It also marks the weakest commitment and level of knowledge of a person to their utterance. Pragmatically, such a person exudes very low confidence but may be identified as a respectful, polite and tactful person which is highly acceptable in the Ghanaian society. Could like may and might, indicates a lower possibility and all the attributes of may.

The following are some instances in the data: 
1) Let us join in the great challenge that the almighty has laid before us to so transform our country in the years to come that we may be the ultimate beneficiaries of a prosperous nation under God. (J. E. A. MILLS2009)

2) We are a blessed people and with God's guidance our smiles might even become laughter in the not too distant future. (J. A. KUFUOR2001)

3) May God bless our homeland Ghana and make us greater and strong. (J. D. MAHAMA2013)

4) The opportunities posed by these gains could result in self-sufficiency. (J.

\section{MAHAMA2013)}

5) The change can start now and with us individuals. (N. AKUFO ADDO2017)

6) Complacency and frustration can entice us. (J. D. MAHAMA2013)

In this section, it would be noticed that, the various levels of epistemic modality in political discourse are used to indicate different communicative functions and purposes. First, speakers use High value EM markers to indicate the closeness of their proposition or comments to the notion of certainty. It is also used to show that the speaker is a confident and a bold person and because of this, he is seen as undemocratic. The medium value we noted is usually used when the speaker has no sufficient knowledge about the proposition and so is very diplomatic and tentative in making statements. This type of speaker is considered democratic as he does not make categorical statements and leaves room for other's view. With the low value, the speaker does not only show weak commitment to his statements because they are not sure of the information, but because they want to be polite and considerate to their audience. At this level too, the speaker uses hedges especially in the Ghanaian context were hedging one's speech is a mark of a good and a respectful speaker. It is therefore worth noting that many a Ghanaian president is both communicatively sensitive and reliant in their inaugurals.

\section{Conclusion}

From the corpus-based analysis of the data, it was found that the notion of EM in the selected inaugurals was coded by only four linguistic categories according to Halliday's (1994) concept of EM (modalisation). These categories are: modal verbs, lexical verbs, adverbials and adjectives. Among these, modal verbs were the most used with a frequency count of 165. This finding corroborates Hoye's (1997), who postulates that EMs are the most frequently used linguistic strategies by which political leaders especially presidents express their conviction or assessment of a proposition in terms of their truth-value or otherwise. It was discovered that markers of EM of high value or strength were dominantly used with $65.4 \%$ of epistemic strength while markers of low EM were $15.4 \%$. While this finding contradicts Milkovich (2017) and Xu (2015) who conclude that politicians usually employ more markers of EM of medium value in their speeches, it agrees with Jantuah (2008) and Adu (2015) who claim that, assertives (high modality markers) usually dominate in political speech analysis especially in 
distance. This difference is however resolved by Trosborg (2000) who posits that because presidents are usually less compelled to be persuasive in their inaugurals, they are more categorical in their propositions to win the trust and confidence of the citizenry; hence their use of high EM markers. Because the presidents are epistemically high, they are considered confident, reliable and bold. The moderate use of indicators of both medium and low epistemic values portrays the presidents as polite, diplomatic and communicatively sensitive. It is observed that the choice of a specific EM marker was informed by a specific communicative intent and context.

This work has theoretical, pedagogical and practical significance. Theoretically, it expands knowledge in epistemic study by indicating that EM in the interpersonal metafunction plays pragmatic reasons such as politeness, stance-taking and identity-construction especially in the Ghanaian context. Again it gives credence to the hypothesis that modal verbs are the major linguistic category that is used to express EM. Pedagogically, it serves as a reference material for both teachers and students who aspire to get a better grasp of the concept of EM. And practically too, it is a good reference point for political discourse analysts and writers as to why and when a particular EM marker should be used.

\section{Conflicts of Interest}

The authors declare no conflicts of interest regarding the publication of this paper.

\section{References}

Adu, E. J. (2015). Epistemic Modality in Political Discourse-A Study of Two Selected State of the Nation Addresses by Ex-President John A. Kufuor of Ghana. Unpublished M.Phil. Thesis. http://www.macrothink.org/journal/index.php/ijl/article/view/799

Baker, P. (2014). Using Corpora to Analyze Gender. London: Bloomsbury.

Brown, P., \& Levinson, S. (1987). Politeness: Some Universals in Language Usage. Cambridge: Cambridge University Press. https://doi.org/10.1017/CBO9780511813085

Bybee, J. L., \& Fleischman, S. (1994). Modality in Grammar and Discourse: An Introductory Essay. In J. L. Bybee, \& S. Fleischman (Eds.), Modality in Grammar and Discourse (pp. 1-14). Amsterdam: John Benjamins. https://doi.org/10.1075/tsl.32

Campbell, K. K., \& Jamieson, K. H. (2008). Deeds Done in Words: Presidential Rhetoric and the Genres of Governance. Chicago, IL: Chicago University Press.

Coates, J. (1983). The Semantics of Modal Auxiliaries (pp. 27-64). London: Croom, Helm Context and Cognition; Amsterdam: John Benjamins.

Collins, (2009). Modals and Quasi-Modals in English. Amsterdam and New York: Rodopi. https://doi.org/10.1163/9789042029095

Flowerdew, L. (1998). Corpus Linguistic Techniques Applied to Textlinguistics. System, 26, 541-552. https://doi.org/10.1016/S0346-251X(98)00039-6

Fowler, R. (1983). Power. In T. A. vanDijk (Ed.), Handbook of Discourse Analysis (Vol. 4, pp. 61-82). London: Academic Press, Inc.

Halliday, M. A. K. (1971). Introduction to Functional Grammar (pp. 73-98). London: Edward Publication. 
Halliday, M. A. K. (1978). Introduction to Functional Grammar (p. 25). London: Longman.

Halliday, M. A. K. (1985). Introduction to Functional Grammar (2nd ed., p. 15). London: London University Press.

Halliday, M. A. K. (1994). Introduction to Functional Grammar (pp. 73-98). London: Edward Publication.

Halliday, M. A. K. (2004). On the "Architecture" of Human Language. In M. A. K. Halliday, \& J. J. Webster (Eds.), On Language and Linguistics (Vol. 3, The Collected Works of M.A.K. Halliday) (pp. 18, 49). London: London University Press.

Halliday, M. A. K., \& Matthiessen, C. M. I. M. (2004). An Introduction to Functional Grammar(3rd ed., pp. 18, 49, 126, 127, 128). London: Longman.

Hardjanto, T. D., \& Mazia, N. (2019). "We Believe in Democracy...”: Epistemic Modality in Justin Trudeau's Political Speeches. HUMANIORA, 31, No. 2. https://doi.org/10.22146/jh.v31i2.44948

Hart, C., \& Cap, P. (Eds.) (2014). Introduction. In Contemporary Critical Discourse Studies (pp. 1-15). London: Bloomsbury Academic.

Hoye, L. (1997). Adverbs and Modality in English. London: Longman.

Israel, P. C., \& Botchwey, E. (2017). Language and Politics: A Study of Presidential Speeches of Selected Ghanaian Leaders. WORD Journal of the International Linguistic Association, 24-43.

Jantuah, B. S. (2008). An Exploration of the Use of Assertive in Ghanaian Presidential Inaugural Addresses. Cape Coast: University of Cape Coast Press.

Klinge, A., \& Muller, H. H. (Eds.) (2010). Introduction. In Modality: Studies in form and function (pp. 1-4). Equinox Publishing Limited.

Leech, G., \& Svartvik, J. (1997). A Communicative Grammar of English (2nd ed., p. 75). London: Pearson Educational Limited.

Lyons, J. (1977). Linguistics: An Introduction to General Linguistics (2nd ed., pp. 43-805). Oxford: OUP.

Milkovich, S. (2017). Epistemic Modality in Political Discourse. Research Result: Social Studies and Humanities, 3, 75-79.

Nemickienè, Z. (2019). Means of Expression of Epistemic Modality in Russian Political Discourse. Respectus Philologicus, 36, 19-31. https://doi.org/10.15388/RESPECTUS.2019.36.41.20

Ngula, R. S. (2015). Epistemic Modality in Social Science Research Articles Written by Ghanaian Authors: A Corpus-Based Study of Disciplinary and Native vs. Non-Native Variations. Doctoral Dissertation, Lancaster: Lancaster University.

Nordquist, R. (2003). The Auxiliary Verb (pp. 2-3). Cambridge: Cambridge University Press.

Nuyts, J. (2001). Epistemic Modality, Language, and Conceptualization: A Cognitive-Pragmatic Perspective. Amsterdam: John Benjamins Publishing Company. https://doi.org/10.1075/hcp.5

Opeyemi, M. O., \& Ajoke. I. O. (2019). Linguistic Modality in Ghanaian President Nana Addo Dankwa Akufo-Addo's 2017 Inaugural Address. European Journal of Social Sciences, 58, 134-142.

Palmer, F. R. (1989). Mood and Modality (2nd ed., p. 20). Cambridge: Cambridge University Press.

Palmer, F. R. (2001). Mood and Modality. Cambridge: Cambridge University Press. 
https://doi.org/10.1017/CBO9781139167178

Palmer, R., \& Jacobson, R. (1974). Readings in English Transformational Grammar (pp. 2, 37). Waltham: Mass. Press.

Perkins, M. (1983). Modal Expressions in English. London: Pinter Perspective; Oxford: Oxford University Press.

Pham, K. T. (2010). An Investigation into Modality Markers Used in Political Speeches by United States' Presidents. M.A. Dissertation, Da Nang: Danang University.

Thompson, G., \& Hunston, S. (Eds.) (2004). Evaluation in Text: Authorial Stance and the Construction of Discourse (pp. 1-27). Oxford: Oxford University Press.

Trosborg, A. (2000). The Inaugural Address: President Clinton's 1993 Address. John Benjamins Publishing Company. https://doi.org/10.1075/pbns.74.11tro

VanDijk, T. A. (2011). Discourse, Knowledge, Power and Politics: Towards critical Discourse Studies. 2 (pp. 189-194). Dongguk: Dongguk University Press.

Vold, E. T. (2006). Epistemic Modality Markers in Research Articles. A Cross-Linguistic Functional and Corpus Approaches (pp. 216-228). London: Hodder and Stoughton.

White, R. R. (2003). Beyond Modality and Hedging (p. 87). Detroit, MI: MacMillan.

Wilson, D., \& Sperber, D. (2001). Mood and the Analysis of Non-Declarative Sentences. (pp. 30-401). Redwood City, CA: Stanford University Press.

$\mathrm{Xu}$, Z. (2015). Modality and Evidentially in Political Discourse: A Cognitive-Functional Account. Doctoral Dissertation, Lancaster: Lancaster University.

Zeng, Z., \& Wang, J. (2019). A Comparative Study of Interpersonal Function Political Speeches-A Case Study of Inaugural Speeches by Theresa May and David Cameron Theory and Practice in Language Studies, 9, 307-312. https://doi.org/10.17507/tpls.0903.08

Zheni, T. (2019). Socio-Political Dimensions of the Speaker's Cognition in Political Discourse. International Journal of Humanities and Social Science, 9, 135. 